\title{
Recent methods for diagnosis of diabetes mellitus
}

\author{
Available online at www.ijistweb.com \\ RESEARCH ARTICLE \\ Kuldeep Tiwari, Dinesh Kumar \\ Sri Satya Sai University of Technology \& Medical Sciences, Sehore-466001 \\ *Corresponding Author's E-mail: om11agra85@gmail.com
}

\begin{abstract}
The diagnostic criteria for Diabetes mellitus have been modified from those previously recommended by the NDDG or WHO. Three ways to diagnose Diabetes are possible, and each must be confirmed, on a subsequent day, by any one of the three methods. For example, one instance of symptoms with casual plasma glucose $>200 \mathrm{mg} / \mathrm{dl}$ (11.1 $\mathrm{mmol} / \mathrm{l})$, confirmed on a subsequent day by 1$\left.)^{\wedge} \mathrm{PG}>126 \mathrm{mg} / \mathrm{dl}(7.0 \mathrm{mmol} / \mathrm{l}), 2\right)$ an OGTT with the 2 - $\mathrm{h}$ postload value $>200 \mathrm{mg} / \mathrm{dl}(11.1 \mathrm{mmol} / \mathrm{l})$, or 3$)$ symptoms with a casual plasma glucose $>200 \mathrm{mg} / \mathrm{dl}(11.1 \mathrm{mmol} / \mathrm{l})$, warrants the diagnosis of Diabetes.For epidemiological studies, estimates of Diabetes prevalence and incidence should be based on an FPG $>126 \mathrm{mg} / \mathrm{dl}(7.0 \mathrm{mmol} / \mathrm{l})$. This recommendation has been made in the interest of standardization and also to facilitate field-work, particularly where the OGTT may be difficult to perform and where the cost and demands on participants' time may be excessive.
\end{abstract}

Keywords: Diabetes, Diagnosis, Glucose, Regulation.

\section{Introduction}

Diabetes Mellitus is a metabolic disturbance characterised by hyperglycaemia and a relative lack, or complete absence of insulin (1). It is a disease, which by virtue of its complications may affect all organ systems in the body. Prevention, timely diagnosis, and treatment are important in patients with diabetes mellitus. Many of the complications associated with diabetes, such as nephropathy, retinopathy, neuropathy, cardiovascular disease, stroke, and death, can be delayed or prevented with appropriate treatment of elevated blood pressure, lipids, and blood glucose (2).

Diabetes mellitus and lesser forms of glucose intolerance, particularly impaired glucose tolerance, can now be found in almost every population in the world and epidemiological evidence suggests that, without effective prevention and control programmes, diabetes will likely continue to increase globally $(3,4)$. In 2010, about 285 million people in the age group 20-79 were envisaged to have diabetes worldwide, about $70 \%$ of who live in developing nations. This estimate is expected to increase to about 438 million, by 2030 (5-8). Further, by 2030 , the number of people with IGT is projected to increase to 472 million, or $8.4 \%$ of the adult population. The debilitating effects of diabetes mellitus include various organ failures, progressive metabolic complications such as retinopathy, nephropathy, and/or neuropathy (9-11). Diabetics are accompanied by risk of cardiovascular, peripheral vascular and cerebrovascular diseases. Several pathogenetic processes are involved in the development of diabetes, including destruction of pancreatic $\beta$-cells that lead to lowered sensitivity of insulin action (12$15)$.

Estimated total annual cost associated with diabetes in Latin America and the Caribbean to be US\$65.216 billion. With a prevalence of 200,000 type 1 diabetics in India, estimated that the cost of treatment could be as high as US\$50 million (16). According to American Diabetes Association, the combined direct and indirect costs of diabetes in 1997 were estimated at US $\$ 98$ billion in the United States of America. The estimated total direct cost of diabetes in Spain is over US\$650 million where there were over 1.4 million known diabetics in 1994 (Hart et al., 1997). In England and Wales, the estimated cost of type 1 diabetes is US\$1.92 million (Gray and Fenn, 1995). Unfortunately, there is a dearth of similar evidence for the WHO African Region. The growing burden of diabetes and other noncommunicable diseases is one of the major health challenges to economic 
developments bedeviling WHO African Region states. As Kirigia et al. (2009) indicate, the effectiveness of prevention and control of those illnesses rely largely on the performance of health systems, functions of leadership and

Table 1 Most common cause of Monogenic Diabetes governance; health workforce; medical products, vaccines and technologies; information; financing; and services delivery (17).

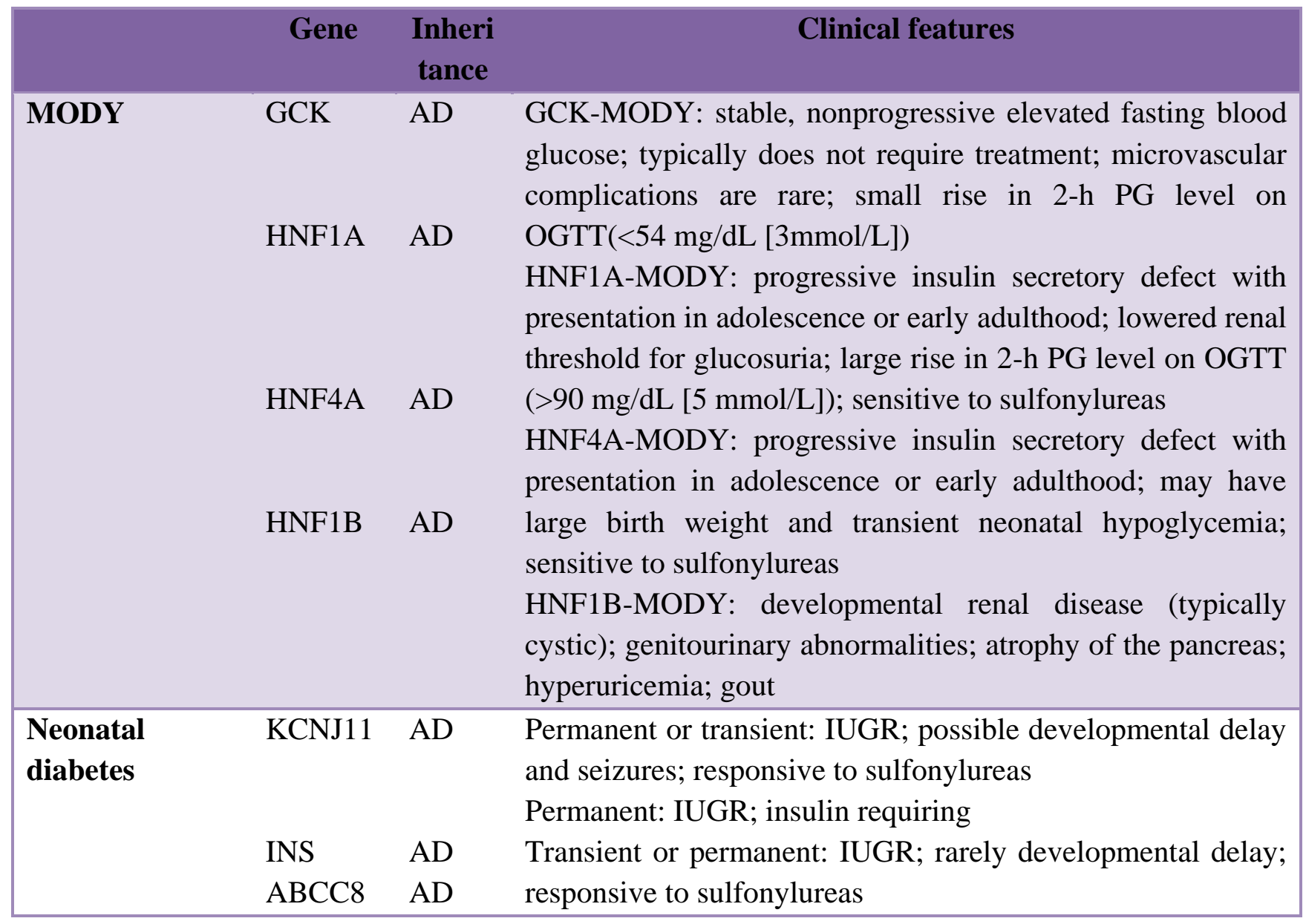

\section{Materials and Methods}

The research methodology adopted for the study is discussed. The methodology of the research includes the research design, description of the setting, population, sample, sampling technique and development of the tool, procedure for data collection and plan for data analysis. Efforts for improved criteria for diagnosis \& classification started a decade before Von Mering \& Minkowski's work.

\section{Urine Tests}

Urine tests are undertaken to analyse ketones bodies, glucose and proteins in the urine. The colorimetric reaction that occurs between ketones and nitroprusside (Sodium nitroferricyanide) is the method used for the rapid semiquantitive measurements of ketones (18).

\section{Maturity-Onset Diabetes of the Young}

Maturity Onset Diabetes of the Young (MODY), represents a rare cause of diabetes (1\% of all cases), commonly misdiagnosed as Type 1 Diabetes (T1D) or Type 2 Diabetes (T2D). Clinical characteristics of MODY include age of onset before 45 years, absence of beta-cell autoimmunity and features of metabolic syndrome, sustained endogenous insulin production and strong family history. Common reasons for misdiagnosis are limitations in physicians' awareness and restrictions in performing genetic testing. In an attempt to improve diagnosis rates, recent research efforts have focused on the discovery of non-genetic biomarkers for prioritising 
individuals for genetic testing, with some promising progress (identification of highsensitivity CRP, plasma glycan profile as HNF1A-MODY).

\section{Post-Transplantation Diabetes Mellitus}

Post-transplant diabetes mellitus (PTDM) is common after most types of solid organ transplantation, though the actual incidence is as yet unknown because of the use of different diagnostic criteria. PTDM is the result of individual risk factors as well as risk factors associated with the transplant itself, particularly immunosuppressants. Previously called New Onset Diabetes, in many cases inadequate screening for diabetes before transplant cannot assure that the diabetes is new after transplant. The most recent international consensus guidelines suggest diagnosis should be delayed until the patient is taking maintenance doses of immunosuppressants even if they require treatment in the immediate hospitalization.

\section{Results and Discussion}

\section{Neonatal Diabetes}

We enrolled 32 patients diagnosed with diabetes before 6 months of age and 45 patients diagnosed between 6 and 12 months. We identified a mutation in KCNJ11 in 14 patients from 12 families and in INS in 7 patients from 4 families. Three of the patients with an INS mutation were diagnosed with diabetes between 6 and 12 months of age. Finally, we found that two patients had an abnormality of chromosome 6q24 associated with transient neonatal diabetes mellitus.

\section{Maturity-Onset Diabetes of the Young}

Patients are generally asymptomatic and are diagnosed incidentally or as part of screening for diabetes, e.g. pregnancy. In pediatric populations, GCK-MODY was found to represent $40-50 \%$ of cases of asymptomatic or incidental hyperglycemia It is inherited in an autosomal dominant pattern with abnormalities in at least 13 genes on different chromosomes identified to date. The most commonly reported forms are GCKMODY (MODY2), HNF1AMODY (MODY3), and HNF4A-MODY (MODY1). Clinically, patients with GCKMODY exhibit mild, stable, fasting hyperglycemia and do not require antihyperglycemic therapy except sometimes during pregnancy. Patients with HNF1A- or HNF4A-MODY usually respond well to low doses of sulfonylureas, which are considered first-line therapy. Mutations or deletions in HNF1B are associated with renal cysts and uterine malformations (renal cysts and diabetes [RCAD] syndrome). Other extremely rare forms of MODY have been reported to involve other transcription factor genes including PDX1 (IPF1) and NEUROD1.

\begin{tabular}{|c|c|c|c|c|c|}
\hline Characteristic & T1 D & T2D & HNF1A/HNF4A-MODY & GCK-MODY & PNDM \\
\hline $\begin{array}{l}\text { Typical a at } \\
\text { diagnosis }\end{array}$ & $\begin{array}{l}6 \text { months-young } \\
\text { adulthood }\end{array}$ & $>25$ years & 15.45 years & $\begin{array}{l}\text { Mild fasting } \\
\text { hyperglycemia } \\
\text { from birth }\end{array}$ & 0.12 months \\
\hline $\begin{array}{l}\text { Family history of } \\
\text { diabetes }\end{array}$ & $10 \%$ of cases & $\begin{array}{l}>50 \% \text { in young } \\
\text { onset }\end{array}$ & $50-100 \%$ of cases ${ }^{1}$ & Common $^{2}$ & $10 \%$ of cases \\
\hline B-cell antibodies & $\sim 90 \%$ at diagnosis & Negative & Rare & Rare & Negative \\
\hline C-peptide levels & Low-undetectable & Normal/high & Normal & Normal & Low $^{3}$ \\
\hline $\begin{array}{l}\text { Diabetic } \\
\text { Ketoacidosis }\end{array}$ & Common & Rare & Rare & Rare & Common \\
\hline hsCRP & Normal & $\begin{array}{l}\text { Mild chronic } \\
\text { elevation }\end{array}$ & Low & Normal & Not assessed \\
\hline DG9 glycan index & Normal & Normal & Low & Normal & Not assessed \\
\hline $\begin{array}{l}\text { First line } \\
\text { treatment }\end{array}$ & Insulin & $\begin{array}{l}\text { Oral } \\
\text { hypoglycemics }\end{array}$ & $\begin{array}{l}\text { Low dose of } \\
\text { Sulphonylureas }\end{array}$ & None & $\begin{array}{l}\text { KCNJ11/ABCC8 } \\
\text { high dose } \\
\text { sulphonylureas } \\
\text { Others: Insulin }\end{array}$ \\
\hline $\begin{array}{l}\text { Micro/ } \\
\text { macrovascular } \\
\text { complications }\end{array}$ & Yes & Yes & Yes & Rare/unknown & Yes \\
\hline
\end{tabular}


The clinical presentations of the different MODY subtypes differ, particularly in the severity and the course of the insulin secretion defect, the risk of microvascular complications of diabetes, and the defects associated with diabetes. Patients with MODY2 have mild, asymptomatic, and stable hyperglycemia that is present from birth. They rarely develop microvascular disease, and seldom require pharmacologic treatment of hyperglycemia. In patients with MODY3, severe hyperglycemia usually occurs after puberty, and may lead to the diagnosis of type 1 diabetes. Despite the progression of insulin defects, sensitivity to sulfonylureas may be retained in MODY3 patients. Diabetic retinopathy and nephropathy frequently occur in patients with MODY3, making frequent follow-up mandatory. By contrast, other risk factors are not present in patients with MODY and the frequency of cardiovascular disease is not increased. The clinical spectrum of MODY is wider than initially described, and might include multiorgan involvement in addition to diabetes. In patients with MODY5, due to mutations in hepatocyte nuclear factor-1beta, diabetes is associated with pancreatic atrophy, renal morphologic and functional abnormalities, and genital tract and liver test abnormalities. Although MODY is dominantly inherited, penetrance or expression of the disease may vary and a family history of diabetes is not always present. Thus, the diagnosis of MODY should be raised in various clinical circumstances. Molecular diagnosis has important consequences in terms of prognosis, family screening, and therapy.

\section{Post-Transplantation Diabetes Mellitus}

Currently, oGTT is considered as a golden standard for the diagnostics of PTDM. In the event of applying oGTT, the incidence of PTDM is significantly higher compared to the postprandial monitoring of glycaemia or applying HbA1c. oGTT allows diagnosing the disorder of glucose tolerance, which is a significant risk factor for development of PTDM

Criteria for diagnosis follow those of the American Diabetes Association and the World Health Organization, although hemoglobin A1C should not be used as the only screening test at least until one year after transplant because of its insensitivity for significant glucose intolerance in the transplant patient and setting. Management of PTDM is best done in a team setting, with an emphasis on glycemic control, dyslipidemia, and hypertension, and taking into consideration immunosuppressant regimens and potential drug side effects and interactions. While PTDM has been associated with changes in outcomes, these have and may continue to improve with improved diabetes care in and out of the hospital, and other changes in post-transplant care

The OGTT is considered the gold standard test for the diagnosis of PTDM. However, screening patients using fasting glucose and/or A1C can identify high-risk patients requiring further assessment and may reduce the number of overall OGTTs required.

There is currently a lack of clinical data examining the use of anti-diabetes agents in the setting of PTDM to inform specific recommendations for use in this population. Although the use of immunosuppressive therapies is a major contributor to the development of PTDM, the risks of transplant rejection outweigh the risks of PTDM and the role of the diabetes care provider is to treat hyperglycemia appropriately regardless of the type of immunosuppression.

\section{Cystic Fibrosis-Related Diabetes}

CFRD mortality has significantly decreased over time, and the gap in mortality between cystic fibrosis patients with and without diabetes has considerably narrowed. There are limited clinical trial data on therapy for CFRD. The largest study compared three regimens: premeal insulin as part, repaglinide, or oral placebo in cystic fibrosis patients with diabetes or abnormal glucose tolerance. Participants all had weight loss in the year preceding treatment; however, in the insulin-treated group, this pattern was reversed, and patients gained 0.39 (6 0.21) BMI units (P 5 0.02). The repaglinide-treated group had initial weight gain, but this was not sustained by 6 months. The placebo group continued to lose weight. Insulin remains the most widely used therapy for CFRD.

Recommendations for the clinical management of CFRD can be found in the ADA position statement "Clinical Care Guidelines for 
Cystic Fibrosis-Related Diabetes: A Position Statement of the American Diabetes Association and a Clinical Practice Guideline of the Cystic Fibrosis Foundation, Endorsed by the Pediatric Endocrine Society".

\section{Conclusion}

The diagnostic criterion for the diagnosis of diabetes mellitus has been undergoing review globally. The American Diabetes Association (ADA) and the World Health Organization (WHO) have always released differing recommendations regarding the criteria for diagnosis of diabetes mellitus. For instance, in 2003 the ADA modified its recommendations resulting in discrepancies between its recommendations and those of the WHO.

We were able to establish a genetic cause of diabetes in $63 \%$ of patients diagnosed with diabetes before 6 months of age and in $7 \%$ of patients diagnosed between 6 and 12 months. Genetic testing, which is critical for guiding appropriate management, should be considered in patients diagnosed with diabetes before $1 \mathrm{yr}$ of age, especially if they are autoantibody negative, although the presence of autoantibodies does not rule out a monogenic cause.

Overall, the practical implications of these reports for clinical practice are that the diagnosis of diabetes in people with classic symptoms should be established with a random plasma glucose concentration of $>11.1 \mathrm{mmol} / \mathrm{l}$, preferably repeated or confirmed by a raised fasting glucose value on a subsequent day. In less clear cases the diagnosis can be established with a fasting plasma glucose of $>7.0 \mathrm{mmol} / \mathrm{l}$, again repeated on a different occasion. Although the American Diabetes Association report was published as the final findings of its expert committee, the paper from the WHO is labelled as a provisional report.

Clinicians managing patients with diabetes need to have an understanding of the individual patient's pathophysiology that underpins their classification as this will significantly help in the clinical management and risk stratification for diabetes chronic vascular complications.

\section{Acknowledgement}

The authors are thankful to IJIST Journal for publishing their article.

\section{Conflicts of Interest}

The author declares that there are no conflicts of interest.

\section{References}

1. Souhami R, Moxham J, Diabetes Mellitus and disorders of lipid and intermediary metabolism. Churchill Livingston, London, 1994.

2. American Diabetes Association, "Standards of medical care in diabetes", Diabetes Care, 2010; 33(1):S11-S61, 2010.

3. Adachi T., Ohta H., Yamada H., Futenma A., Kato K., Hirano K., Quantitative analysis of extracellularsuperoxide dismutase in serum and urine by ELISA with monoclonal antibody. Elsevier, 2007; 212(3):1128.

4. Halkjaer J., Thorkild S., Anne J. T., Togoper CH, Berit HL., Food and Drinking Patterns as Predictors of 6 Year BMI- Adjusted Changes In Waist Circumstance, British Journal of Nutrition, 2004; 92:735-748.

5. Belay A., Kato T., Ota Y., Spirulina (Arthrospira): Potential Application as an Animal Feed Supplement, J Appl Phycol, 1996; 8:303-311.

6. Belay A., Ota Y., Miyakawa K., Shimamatsu H., Production of High Quality Spirulina at Earthrise Farms. In: Phang SM, editor. Algal Biotechnology in the Asia Pacific Region, Kuala Lumpur: University of Malaya, 1994, Pp. 92-102.

7. Janka H.V. and Michaelis D., Epidemiology Of Diabetes Mellitus, Prevalene, Incidence, Pathogenesis And Prognosis, German Article, 2003; 96(3):159-165.

8. Jannette C., Brand M., Susanna H. A., Holt D. B., Pawlak and Mcmillan., Glycemic Index And Obesity, American Journal Of Clinical Nutrition, 2002; 28(IS5S):510.

9. Abate $\mathrm{N}$ and Manisha C., Ethnicity and Type 2 Diabetes-Focus on Asian Indians, Journal of Diabetes and it's Complications, 2001; 15:320-327.

10. Campanella L., Elizabetta M., Rita, G., Manuro T., Antioxidant Capacity of Dry Vegetal Extracts Checked by Voltammetric Method, Journal of Food, Agriculture And Environment, 2006; 4:54-56

11. Adams C. A., Nutricines: Food components in Health and Nutrition, Nottingham University Press, Nottingham, 1999, Pp. 16-17.

12. Adèr H. J., Mellenbergh G. J and Hand, D. J., Advising on research methods: A consultant's companion, The Netherlands: Johannes van Kessel Publishing, Netherland, 2008, Pp. 273-278.

13. Canadian Diabetes Association, Guidelines For The Nutritional Management Of Diabetes Mellitus In The New Millennium: A Position Statement By The Canadian Diabetes Association, Canadian Journal of Diabetes Care, 2000; 23:56-69.

14. Dambal S.S., Indumati V., Suchetha Kumari.. Role of Oxidative Stress in Obesity with an Insight into Type Il Diabetes Mellitus, Journal of Clinical and Diagnostic Research, 2011; 5:52-54.

15. Dan Lukaczer N.D., Liska J., DeAnn D., Robert H. L. and Jeffery, S. B., Effect of a Low Glycemic Index 
Diet with Soy Protein and Phytosterols on CVD Risk Factors in Post Menopausal Women, Nutrition, 2006; 22(2):104-113.

16. Drummound E. K., The Customer Check on the Experts, J Am Dietetic Assoc. 1953; 29:552

17. Easwaran P. P., Vidhya, K., Alamelu, M. S., Vasanthamani, G., Impact of Antioxidant Vitamins E and $\mathrm{C}$ on the Lipid Profile of Hyperlipidemics, The
Indian Journal of Nutrition and Dietetics, 2002, Vol: 39, p. 1.

18. Friedemann TE, Sheft BB, Miller VC, “An assessment of the value of nitroprusside reaction for the determination of ketone bodies in urine" Queens Bullettin of Northwestern University Medical School, 1946; 20:301-310. 